\title{
Canadian medical students want more nutrition instruction
}

$\mathrm{C}$ anadian medical students are lacking adequate education in nutrition, and they aren't happy about it, according to a survey distributed to 9 universities across Canada. Of the 933 students who responded to the survey (a $28.6 \%$ response rate), which hasn't been published yet, $87.2 \%$ said their undergraduate medical program should dedicate more time to nutrition education.

"Physicians are becoming increasingly aware of their abysmal training in nutrition," says Dr. Leah Gramlich, president of the Canadian Society for Clinical Nutrition and lead author of the survey. "People still don't think of nutrition as a science, and doctors aren't in a position to refute or substantiate nutrition claims."

Many survey respondents said they were somewhat comfortable in their knowledge of basic nutrition concepts and the role nutrition plays in disease prevention. But they also said they lacked sufficient knowledge about the role nutrition plays in treating diseases, are ill-equipped to counsel patients on their nutrient requirements across all stages of their lives and have trouble identifying credible sources of nutrition information.

Unless more Canadian physicians become leaders in this area, however, the paucity of nutrition education in medical schools appears to be a problem that will persist, says Gramlich, a gastroenterologist at the University of Alberta in Edmonton. "Unless there is a push from outside, in the absence of nutrition physician leaders, it's going to be challenging."

Curricula with skimpy nutrition components aren't unique to Canadian medical schools. A 1997 report from the American Medical Student Association stated that $62.6 \%$ of US medical school students believed they needed more nutrition education. Fewer than half of the US medical schools that participated in a 2006 study required at least 25 hours of nutrition instruction,

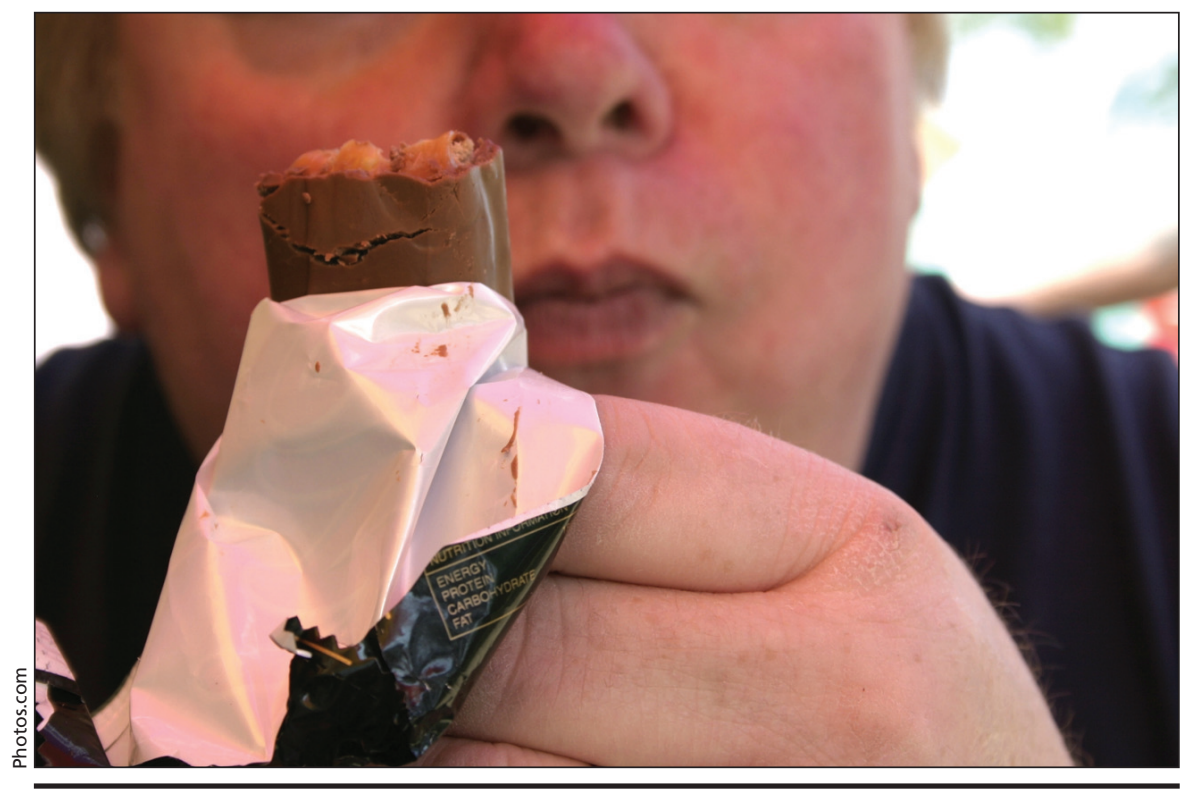

Many Canadian medical students believe they don't receive enough nutrition education and aren't qualified to counsel patients on their nutrition requirements across all stages of their lives, according to a recent survey.

the minimum standard recommended by the National Academy of Sciences (Am J Clin Nutr 2006;83:941S-4S). And $88 \%$ of medical instructors who participated in that study said their institutions needed more nutrition instruction. Surveys conducted in many other countries — such as Bangladesh, Saudi Arabia and Turkey — indicated that many doctors are aware only of nutrition information that has appeared in the medical press.

A 1999 survey on the nutrition knowledge of Canadian physicians found that doctors had poor knowledge of many important nutrition topics, such as the association between excessive protein intake and calcium loss, and the best type of dietary fibre to lower patients' blood cholesterol levels (J Am Coll Nutr 1999;18[1]:26-9).

How much has changed in the ensuing decade?

"What has changed is depressingly little. What it comes down to is that there is a continual war for teaching time in medical schools," says Norman Temple, author of the 1999 survey and a professor of nutrition at Athabasca University in Athabasca, Alberta. "Nutrition is the poor Cinderella that is not invited to the ball."

Medical schools concentrate on how to treat disease with drugs and surgery, and doctors are never taught how to properly counsel patients on changes to diet and lifestyle, says Temple, who recently coedited the Desktop Nutrition Guide for Physicians. "The doctor's office is a pretty lousy place to go for guidance on this. People are badly confused. There is a desperate need for a system of credible sources of good information from credible people. When you go to Chapters, the good books and the bad books are not colour-coded."

Of course, there are other health professionals, such as dieticians, who can help steer people away from fad diets and the glut of unsound nutrition information on the Internet and in magazines. But doctors are in a unique position because they can provide advice at times of acute illness, when it is more likely to resonate, says Corilee Watters, coordinator of Nutrition Service at Van- 
couver Island Health Authority in Victoria, British Columbia.

"Studies have shown that a short, simple message does have an effect," says Watters. "That simple message has an impact on patient behaviour. It's important that physicians are aware of this impact."

Watters teaches nutrition courses to medical students, and says they often tell her that nutrition should be taught earlier in their programs and integrated throughout the curriculum. That would be more likely to happen, she says, if medical faculties had more staff quali- fied to teach nutrition. "We have anatomy professors," she says. "We need nutrition professors."

Some medical schools appear to be moving in that direction. For instance, The University of Ottawa Faculty of Medicine in Ottawa, Ontario, recently appointed a staff member to be the leader on nutrition. The school will now be dedicating a week to obesity education and is in the process of revising its curriculum to include more instruction on nutrition, which staff included in a list of 18 "hot topics" that required greater attention.

"Society tends to focus on different aspects of health at different times and, in general, nutrition has historically not been high up on the list of important topics," says Dr. Geneviève Moineau, associate dean of undergraduate medical education at the University of Ottawa. "I think we now realize that there are so many health issues that directly relate to nutrition, whether we are talking about obesity, eating disorders or other diseases that we now know we can prevent by proper nutrition." - Roger Collier, CMAJ

DOI:10.1503/cmaj.091163

\section{Shortages no more: Fixing the isotope supply chain}

$\mathrm{W}$

hen something as important as the world's medical isotope supply can be compromised by the closure of a single facility, people get worried. With another isotope shortage causing them grief, nuclear medicine practitioners appear worried enough to look beyond short-term workarounds to long-term solutions.

Some nuclear experts are exploring how the world became so dependent on so few reactors. This problem has been of great concern since May, when the reactor in Chalk River, Ontario, went off-line due to a heavy-water leak.

"How did we get ourselves into this corner?" says Jatin Nathwani, Ontario research chair in public policy for sustainable energy management. "If you reflect upon it, this reliance on old and aging reactors as the critical suppliers of medical isotopes, you just shake your head."

Nathwani, a professor of management sciences at the University of Waterloo, has twice appeared before the House of Commons Committee on Natural Resources to discuss this problem. He is not encouraged, however, by the government's announcement that it will stop producing isotopes after the Chalk River reactor shuts down permanently, likely in 2016. Nathwani says this will only create more problems for Canada, making it wholly dependant on other countries. "That is not a credible long-term view."

Dr. Andrew Einstein, an assistant professor of clinical medicine at Colum-

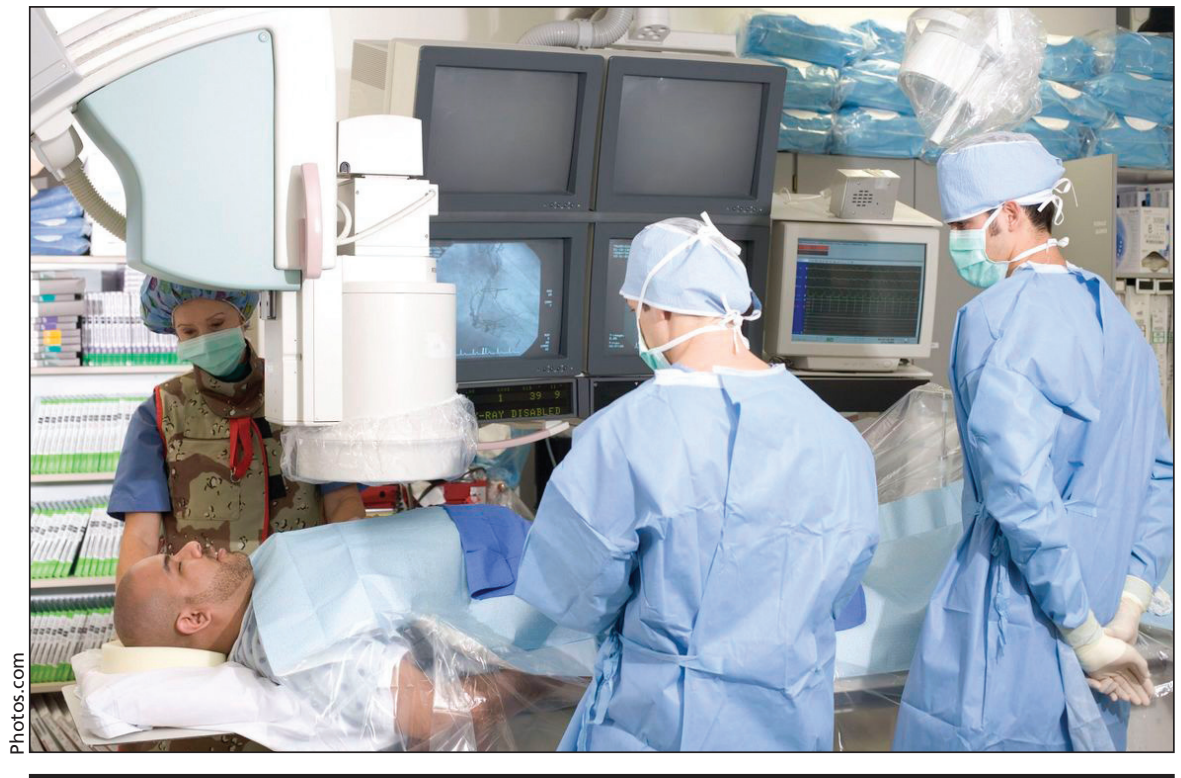

Nuclear medicine practitioners are tired of rescheduling diagnostic procedures because of isotope shortages. They are looking for ways to secure the global isotope supply.

bia University in New York, says some people have suspected the overdependence on a few reactors would lead to trouble. "If you look back in the literature over the past 20 years, you see periodic statements about the tenuousness of the supply," he says. "But as long as the supply was coming, no one challenged the status quo."

Now, however, maintaining the status quo isn't an option, says Einstein. "There is just not enough reserve in the system. There is a need for more reactors so that we are not so dependent on the perfect functioning of the reactors we have."

Some nuclear experts say the problem is not a lack of reactors, but a lack of coordination between parties capable of producing raw isotopes (those with facilities where uranium targets can be irradiated with neutrons) and those capable of processing them into a form for use in nuclear medicine (molybdenum-99). "There are lots and lots of reactors around the world that are underutilized, yearning for someone to buy their neutrons," says Alan Kuperman, director of the Nuclear Proliferation Prevention 